\title{
IMPLICANCIAS PRÁCTICAS DEL LIBERALISMO IGUALITARIO: CRITERIOS DE EQUIDAD TRIBUTARIA*
}

\author{
Cristián A. Fatauros \\ Universidad Nacional de Córdoba - CONICET \\ cristian-fatauros@derecho.unc.edu.ar
}

\section{Resumen}

Este trabajo investiga las implicancias prácticas tributarias de la teoría rawlsiana de la justicia. Para ello se examinan las consideraciones morales que la teoría juzga aplicables al modelo de sociedad denominado "democracia de propietarios". Luego se explicita la manera en que se aplican sus principios en contextos de inequidad social. Finalmente, se consideran dos propuestas de aplicación práctica para basar el sistema tributario sobre los tributos al consumo. Se evalúa si estas propuestas son compatibles con la teoría liberal igualitaria rawlsiana y si colaboran en la promoción de las bases del autorrespeto y la reciprocidad cívica.

PALABRAS CLAVE: Tributos; Justicia contextual; Estructura institucional; Equidad.

\begin{abstract}
This paper explores the tax-related practical implications of rawlsian theory of justice. In order to do that, it scrutinizes the moral considerations that apply to the ideal of "Property-Owning Democracy". Then it addresses the way in which its principles should be applied to circumstances of social unfairness. Finally, it looks at two practical proposals to switch the overall design of tax system to consumption taxes. It evaluates whether these proposals are suitable for a rawlsian egalitarian liberalism theory and whether they help to promote the bases of self-respect and civic reciprocity.
\end{abstract}

KEY WORDS: Taxes; Background justice; Institutional Scheme; Fairness.

\section{Introducción}

Los problemas filosóficos relacionados con la justicia global, la inmigración, la pobreza y la responsabilidad moral han dominado la agenda de la filosofía política contemporánea. Aunque es cierto que el

* Agradezco las críticas y sugerencias de los participantes de seminarios, workshops y conferencias en las que presenté algunas ideas de este trabajo: Congreso Internacional ALFAn II, UBA, Facultad de Derecho de la UPF, Cátedra Hoover de Ética Económica y Social, UCL y Facultad de Derecho y Ciencias Sociales de la UNC. También agradezco las observaciones de los evaluadores anónimos. 
interés por estos temas se debe al importante trabajo filosófico político de John Rawls, una parte del legado rawlsiano ha quedado soslayada. Me refiero al potencial teórico para promover y justificar reformas institucionales tributarias en las sociedades actuales. Para lograr dicha tarea es imprescindible contar con una teoría de la justicia para evaluar la corrección moral de nuestras obligaciones tributarias. En última instancia, esta teoría serviría para promover la educación política, cívica, jurídica y tributaria de ciudadanos que se conciben como libres e iguales. Porque a menos que la concepción política y filosófica que mejor justifica la coacción tributaria sea públicamente conocida y aceptada por todos los ciudadanos, es difícil que ellos puedan concebir sus instituciones tributarias como justas o que cumplan con sus obligaciones movidos por el deseo de justicia. Por ello, uno de los problemas más actuales, relevantes y acuciantes en el diseño institucional de una sociedad bien ordenada es determinar cuáles son las condiciones morales de una distribución equitativa de cargas tributarias. ${ }^{1}$ Podríamos afirmar que el primer problema es la especificación de un criterio de corrección con el cual justificar la crítica (Barry 1989, Rawls 1971/1999, Roemer 1996).

En algunas teorías este criterio se define a partir de una línea de base que establece un patrón distributivo correcto. ${ }^{2}$ Esto conduce a aceptar que los tributos son un medio legítimo para redistribuir recursos cuando la línea de base ha sido transgredida. La distribución desigual de cargas tributarias podría constituirse como un remedio adecuado para restablecer la equidad distributiva. ${ }^{3}$ Además las instituciones tributarias podrían encontrar un límite en la propiedad individual si esta estuviese equitativamente distribuida. ${ }^{4}$ Sin embargo, no es necesario apelar a una línea de base para elaborar un criterio evaluativo de la distribución de cargas tributarias. ${ }^{5}$ Existe una forma más razonable de abordar el

${ }^{1}$ Entre los principales problemas de la justicia y los tributos encontramos: (a) justificación moral de la imposición de la obligación de tributar; (b) utilidad como mecanismo de resolución de problemas de coordinación y cooperación social; (c) distribución adecuada de cargas tributarias; (d) selección de la base imponible adecuada; (e) grado de incidencia tributaria, entre otros (Halliday 2013, pp. 1111-1120).

${ }^{2}$ Nozick (1974), véase también Barry (1989).

${ }^{3}$ Esta es la posición por ejemplo, de los libertarios como Peter Vallentyne y Hillel Steiner (Steiner 2011, Vallentyne 2007, 2012).

${ }^{4}$ Esta posición es sostenida por Robert Nozick (1974). Pero la idea también se encuentra en las concepciones que ven al Estado como un agente que amenaza las libertades individuales; véase Murphy y Nagel (2004) y Holmes y Sunstein 1999).

${ }^{5}$ A pesar de la importancia del problema, no ha sido tratado con profundidad desde el punto de vista de la filosofía política. La obra contemporánea más importante sobre justicia distributiva, A Theory of Justice (Rawls 1971/1999), por ejemplo, dedica solo 
problema que consiste en partir de consideraciones teóricas más generales pero teniendo en cuenta que por sus obvias limitaciones empíricas no pueden definir un sistema de tributos específicos que debieran implementarse. No obstante, pueden ofrecer criterios abstractos y generales como guías de orientación para la reforma. ${ }^{6}$

El objetivo general de este trabajo es evaluar la plausibilidad y la capacidad de la teoría liberal rawlsiana para fomentar el cambio de las instituciones que se consideran injustas o inmorales. Para ello, se investiga la relación entre las instituciones de una sociedad justa y la posibilidad de reformar nuestras propias instituciones a la luz de la teoría. ${ }^{7}$ El plan de trabajo consistirá entonces, en examinar el modo en que los principios de justicia rawlsianos se aplican al diseño institucional tributario y luego analizar dos propuestas de aplicación práctica. Estas propuestas se enfocan hacia los tributos sobre el consumo y una de ellas sobre el consumo ambiental. En la parte final se evalúa si los arreglos institucionales propuestos están destinados solo a incrementar la recaudación o se proponen alcanzar otros objetivos y en su caso si sintonizan bien con una sociedad liberal igualitaria. Intentaré demostrar que la aplicación del valor de la igualdad distributiva al esquema tributario exige la implementación de instituciones que no solo estén

unos párrafos a identificar el sistema tributario de una sociedad justa y esto ha sido criticado (Williamson y O'Neill 2009, p. 3).

${ }^{6}$ El problema de la legitimidad moral de la autoridad estatal se conecta con el problema de la justificación moral de la obediencia general al derecho positivo. La legitimidad de la autoridad es una condición necesaria, pero no suficiente, de la justificación de la obediencia a sus órdenes. Algunos autores sostienen que la justificación de la obediencia general de las órdenes es condición necesaria, pero no suficiente, de que una autoridad sea legítima. En cambio, otros afirman que estas cuestiones tienen una relación de bicondicionalidad. Es decir, una autoridad es legítima si está justificado obedecer sus órdenes y la obediencia de las órdenes de una autoridad está justificada si la autoridad es legítima (Moreso 2004, pp. 125-128). Dada la complejidad de estos problemas, el análisis de las condiciones de legitimidad del poder coercitivo del Estado, y en particular del poder coercitivo tributario, excede los límites de esta investigación.

${ }^{7}$ Rawls ha vinculado la idea de tributos justos con la idea de una "democracia de propietarios", la cual describe una sociedad cuya distribución económica está justificada en el valor de la igualdad y el respeto por la libertad individual. La noción de "democracia de propietarios" fue inicialmente utilizada por el conservadurismo británico y luego introducida en la academia por el economista James Meade, quien concebía este modelo como una ampliación de las instituciones propias del Estado de Bienestar (Jackson 2012, p. 33 y ss.). En la versión rawlsiana, las instituciones sociales y económicas más importantes tienen una justificación moral radicalmente diferente de las inspiradas por el modelo de Estado de Bienestar (Rawls 1971/1999, p. 242 y ss.). 
destinadas a elevar la recaudación impositiva. El valor igual de las libertades políticas es prioritario y no necesariamente exige el incremento de la recaudación fiscal. ${ }^{8}$ Un objetivo adicional del trabajo será ampliar la comprensión de la idea de "democracia de propietarios" rudimentariamente desarrollada por John Rawls.

Dado que esta investigación parte de una teoría ideal de justicia, ella padece de las limitaciones características de esta empresa. Es así que presupone una situación en la que existe un cumplimiento estricto de los principios de justicia, es públicamente conocido que las instituciones realizan una distribución justa y los ciudadanos tienen un sentido de la justicia que los motiva a cumplir con sus obligaciones cívicas. Las conclusiones prácticas que se extraen se refieren a una sociedad cerrada cuyas instituciones regulan las relaciones internas de sus miembros en términos de igualdad y libertad.

\section{II. ¿Reglas de sentido común tributario?}

Para resolver quiénes, qué actividades y cuánto deberíamos tributar podríamos comenzar identificando reglas de sentido común que se aplican al campo tributario y que deberían estar vinculadas con una idea de igualdad. Una de las intuiciones más básicas señala que una sociedad que tratase igualitariamente a sus ciudadanos no debería aplicarles impuestos según criterios basados en circunstancias naturales, sociales, raciales, étnicas o profesionales. Pero no tenemos una respuesta sobre si las personas en situaciones similares deben contribuir de manera igual porque no tenemos una especificación de cuándo las circunstancias son "similares" ni cuándo una contribución es "igual". 9

Otra intuición básica afirma el rechazo de tributos que exigen un

\footnotetext{
${ }^{8}$ Nos referimos a la distinción entre una teoría ideal y una teoría no ideal o de cumplimiento parcial. Esta última analiza las instituciones de una sociedad en la que la satisfacción de los principios de justicia es imperfecta y en la que los ciudadanos cumplen parcialmente con sus obligaciones morales (Rawls 1971/1999, pp. 8, 216 y ss.).

${ }^{9}$ La Constitución Argentina declara: "La igualdad es la base del impuesto y de las cargas públicas" (CN, Art. 16). Ahora bien, determinar las condiciones relevantes para considerar cuándo dos situaciones son semejantes constituye el componente dinámico o variable de una teoría de la justicia. El otro componente, estático o constante, es una teoría de la proporcionalidad o equidad que debe lograr mantener una teoría de la justicia. Véase Hart (1961, pp. 155-159). Se afirma que la noción de equidad horizontal fue primeramente mencionada por Henry Simmons y A. C. Pigou a mediados del siglo XX (véase Elkins 2006, p. 43). El desacuerdo sobre cómo se determina la igualdad horizontal es amplio, pese que su importancia es unánimemente reconocida (Murphy y Nagel 2004, pp. 13, 37-38).
} 
monto fijo per cápita porque esto constituye una inequidad, aunque no se define claramente lo que implica "la equidad tributaria". Alguien podría argumentar que la contribución tributaria debería contabilizar cuánto colabora en la producción social cada ciudadano. Quienes realizan los mayores aportes a la producción social ya han hecho su parte y por ende su contribución impositiva debería ser menor. También podría argumentarse que quienes se benefician más deberían contribuir más. $\mathrm{O}$ argumentarse que para determinar los tributos de una persona deberían contabilizarse sus talentos naturales y sus ganancias potenciales. ${ }^{10} \mathrm{Con}$ lo cual queda claro que no es fácil determinar cuáles son las condiciones que debería satisfacer una imposición equitativa de tributos. ${ }^{11}$

Estas intuiciones de sentido común nos dejan a medio camino. La contribución debe ser igualitaria pero no debe ser exactamente igual. ¿Podría el utilitarismo proporcionarnos criterios para evaluar la estructura institucional tributaria? Si analizamos la teoría consecuencialista bienestarista, pretender evaluar las instituciones sociales con un único criterio de evaluación nos muestra que necesitamos principios no tan básicos como las reglas de sentido común y ciertos criterios jerárquicos para establecer una respuesta clara al respecto (Mill 2001, pp. 57-58, Rawls 1971/1999, p. 268). ${ }^{12}$ El bienestarismo no nos proporciona un criterio para decidir sobre la equidad de la carga tributaria que paga un trabajador. ${ }^{13} \mathrm{Es}$

10 Existe literatura que discute la legitimidad de tomar los talentos productivos como base imponible de esquemas de tributación ideal. Al respecto véase Olson (2010), Shaviro (2002), Stark (2005), Sugin (2010). Rawls, sin embargo, rechaza dicha propuesta por ser violatoria de la prioridad de las libertades básicas. Nadie puede estar obligado a tributar según sus talentos naturales (Rawls 2001, pp. 157-158). La teoría de la igualdad de oportunidades de John Roemer (1998) tendría implicaciones sorprendentes en la determinación de un tributo basado en las oportunidades y capacidades productivas potenciales (véase Fatauros 2012).

11 Estas formas de imponer tributos han sido conceptualizadas como impuestos sobre las ganancias brutas o impuestos al consumo. Los últimos pueden ser pagados de manera previa al consumo, en el momento en que las ganancias ingresan al patrimonio. Esto excluye los ahorros y las ganancias de capital, como es el caso de los impuestos a las ganancias que provienen del trabajo. También pueden ser pagados cuando se consume, es decir cuando egresan del patrimonio (McCaffery 2005, pp. 169-173; 2006).

12 Esta tesis contradice el pluralismo intuicionista que sostiene la irreductibilidad del conflicto de principios morales generales porque niega la existencia de criterios de prioridad (Rawls 1971/1999, p. 30 y ss.). Sobre las reglas de prioridad lexicográfica, véase Rawls (1971/1999, pp. 53-54, 214 y ss.).

${ }^{13}$ Hugo Seleme (2005, p. 143 y ss.) ha expuesto las razones de por qué las teorías morales monistas no pueden dar cuenta de los conflictos de valores. En otra parte he analizado cómo una versión monista del valor sería particularmente vulnerable a la crítica de la nivelación descendente (Fatauros 2014, sección 2.13.1). Una manera de 
decir, es claro que el criterio de evaluación es la maximización de la utilidad (medido como bienestar social), pero no es claro si el esfuerzo personal, las necesidades básicas y/o las preferencias de una persona son relevantes y, por ello, no sabemos si deberíamos gravar la renta, la propiedad o el consumo. Según cuál sea la relevancia moral de estos otros factores, la actividad gravada podría ser distinta y el nivel impositivo también. ${ }^{14}$

Alguien podría argumentar que este no es un problema exclusivo de la teoría consecuencialista bienestarista. Es más, podría argumentar que este problema ni siquiera involucra a las teorías consecuencialistas como el utilitarismo, sino que solo atañe a las teorías deontológicas pluralistas. Pero si el utilitarismo incorporase otras consideraciones valorativas que exigen ser respetadas, como, por ejemplo, el valor del esfuerzo personal, la formación de un plan de vida personal, o la libertad de satisfacer las preferencias propias, la teoría no recomendaría un único curso de acción. Ante esto, tal como afirma Samuel Freeman, la teoría dejaría de ser teleológica, y del mismo modo que las teorías intuicionistas deontológicas, se convertiría en incapaz de identificar de manera clara e indubitable cuál es el curso de acción o la institución moralmente correcta (Freeman 2007, p. 82). Ante esta situación, las reglas de prioridad incorporadas por Justicia como Equidad (Rawls 1999) representan una clara ventaja. ${ }^{15}$

\section{Reglas e intuiciones en Justicia como equidad}

Ahora bien, al permitir la propiedad de bienes de producción en manos privadas, las teorías liberales igualitarias deben enfrentar ciertos problemas vinculados con las grandes concentraciones económicas. Aunque ningún liberal negaría el valor de la autonomía individual, el que algunos individuos sean inmensamente ricos violenta el valor de la igualdad distributiva. El hecho de que existan grandes cantidades de recursos en pocas manos desequilibra el acceso a las profesiones y cargos

superar esa crítica es a través del pluralismo de valores, pero una teoría monista de la utilidad, por ejemplo, aunque no sería vulnerable a la crítica de la nivelación descendente, podría ser incapaz de resolver los conflictos entre diferentes actitudes involucradas en la promoción de la utilidad.

14 ¿Cuál es el modo moralmente correcto de gravar la riqueza de las personas: mediante impuestos al consumo o mediante impuestos a las ganancias? Dicho de otro modo, ¿debemos determinar el monto que cada persona debe contribuir al momento en que ingresa el dinero a su patrimonio o en el momento en que lo usa? (McCaffery 1994, 2006, Murphy y Nagel 2004, Slemrod y Bakija 2008).

${ }^{15}$ Agradezco la observación de un evaluador anónimo. 
sociales más importantes e introduce desventajas políticas. ${ }^{16}$ En Rawls (1971/1999) se desarrolla la idea de una "democracia de propietarios" como modelo de sociedad justa en la que se asegura:

1) Iguales libertades básicas y un sentido del respeto por sí mismo (igual participación política, libertad de opinión, de reunión, de contratación, de circulación, de ocupación, de comercio, de disponer de cierta propiedad privada).

2) Oportunidades sociales equitativas (libre acceso a los cargos según el mérito, acceso a oportunidades educativas para desarrollar sus capacidades ciudadanas y personales, acceso a servicios de salud adecuados).

3) Recursos económicos iguales a menos que la desigualdad beneficie a los que reciben la porción menor.

Mientras que el desarrollo de un modelo socialista de producción y mercado prontamente recibió atención (Cohen 2009, Roemer 1996, 1998; Van Parijs 1992) la idea de una "democracia de propietarios" ha generado interés hace relativamente poco tiempo (O'Neill 2009, O'Neill y Williamson 2012, Williamson y O'Neill 2009). Incluso Rawls (1971/1999) en el prefacio para la edición revisada expresa su intención de profundizar el contraste entre un "Estado bienestarista" y una "democracia de propietarios" para que se aprecie mejor la fuerza del principio de la diferencia y su ideal de reciprocidad subyacente.

De acuerdo con James Meade, quien fue el primero en desarrollar el concepto de "democracia de propietarios", las instituciones deberían apuntar a mantener la igualdad económica de los ciudadanos en general (mediante beneficios sociales y participación de los trabajadores en las ganancias de las empresas), y establecer políticas para acrecentar la propiedad de los que menos tengan (mediante una tributación fuertemente progresiva). Según Meade, la amplia dispersión de la propiedad privada fortalece el sentido de la seguridad, la independencia y la libertad individual (Meade 2013, p. 39). Sin embargo, a diferencia de Rawls, la propuesta de Meade definitivamente incluiría una política de ingreso básico universal (Jackson 2012, p. 46; cf. Rawls 1999).

En la concepción rawlsiana de la "democracia de propietarios" el diseño tributario regula quiénes son los poseedores exclusivos de los medios de producción y define qué pueden hacer con ellos; además

${ }^{16}$ El conflicto entre la autonomía familiar, el mérito y la igualdad de oportunidades reales solo es verdadero cuando se interpretan de manera extrema (Rivera López 2007) también publicado con algunas diferencias como "¿Es el trilema de Fishkin un verdadero trilema?" en Rivera López (1996). 
procura una amplia distribución de la riqueza, para evitar poner en peligro la igualdad de libertades y oportunidades sociales. Asimismo, los tributos tienen un fin recaudatorio pero solo para asegurar un nivel de ingresos que al menos permita satisfacer necesidades básicas y maximizar la posición de los que están peor (Rawls 1971/1999, pp. 245246). Seguidamente reconstruyo los lineamientos aplicables a una sociedad bien ordenada.

\section{III.1. Los impuestos directos y el principio de la diferencia}

El principio de la diferencia exige que las desigualdades económicas beneficien a los más desaventajados. Esto requiere de medios institucionales específicos para evitar que la distribución de bienes económicos sea moralmente arbitraria. Así, las ganancias obtenidas sobre la base de factores moralmente arbitrarios (como por ejemplo, ser heredero de una fortuna o tener talentos productivos) solo están justificadas si mejoran la posición de los que están en la posición distributiva más baja (Rawls 1971/1999, p. 245 y ss.). En el sistema tributario esto implicaría que el grado de incidencia tributaria debería eliminar progresivamente las desigualdades que se generen, pero si, por ejemplo, algunas exenciones impositivas para los que ganan más producen beneficios económicos para los que ganan menos, entonces esas desigualdades no son injustas.

Los tributos deberían progresivamente eliminar desigualdades como las que resultan de las transferencias a título gratuito (herencias y legados). El beneficio que obtienen los herederos se basa en una circunstancia moralmente arbitraria, el hecho de haber nacido en una cierta familia. Este hecho es tan azaroso como la posesión de talentos extraordinarios. Por esta razón la tasa de progresividad de los tributos sobre las herencias y legados podría ser mayor a medida que el azar sea mayor, o el impacto económico en el patrimonio personal de los herederos sea mayor. $\mathrm{O}$ en tanto la naturaleza de la relación entre el causante y el heredero sea más cercana a un tipo de relación "determinada por factores arbitrarios" (Alstott 2007, p. 507 y ss.).

No obstante, la desigualdad económica entre los que están mejor y los que están peor no es lo único relevante. La protección de la igualdad en el valor de las libertades políticas exigida por el principio de la igual libertad también es importante. Es incluso más importante. Para garantizar dicha igualdad es necesario lograr la dispersión amplia de la propiedad privada de los medios de producción implementando impuestos directos sobre la propiedad privada de los medios de producción, pero también de los inmuebles (Rawls 1971/1999, p. 245). 
Este sistema de tributos está justificado por el objetivo que se busca promover, i.e. evitar la acumulación excesiva de riquezas. La acumulación excesiva es preocupante porque lesiona el equilibrio que supone la igualdad de libertad de ocupación, de expresión y de acceso a los diferentes bienes culturales, educativos y sanitarios. Además, si las posiciones y las oportunidades sociales solo están disponibles para los más poderosos económicamente, los económicamente excluidos podrían ver socavada su confianza para alcanzar mejores posiciones y oportunidades.

\section{III.2. Los impuestos indirectos y las libertades iguales}

Ahora bien, de jerarquía mayor, el principio de la igual libertad exige que cualquier ciudadano pueda disfrutar de un nivel de vida decente y que tenga sus necesidades básicas satisfechas. Por razones obvias, la satisfacción de estas exigencias no puede dejarse en manos de la libre oferta y demanda de bienes y servicios. ${ }^{17}$ Hace falta la intervención del Estado para garantizar a los ciudadanos mínimos estándares de vida independientemente de sus capacidades productivas. ${ }^{18}$

Una posible interpretación del ideal de igual libertad podría favorecer una noción de contribuciones económicas estrictamente iguales. Dado que las cargas tributarias pueden concebirse en términos de restricciones a la libertad económica, si todos debiesen disfrutar iguales libertades, esto implicaría que todos soportasen iguales cargas tributarias. El problema es que las cargas tributarias estrictamente iguales no tratan como iguales a quienes tienen diferentes capacidades productivas o diferentes ingresos económicos. Por un lado, incluso aceptando que las libertades deban ser iguales para todos, la contribución podría estar conectada con el valor de las libertades. Una libertad será más valiosa para quien pueda ejercer efectivamente esa libertad y los mayores ingresos económicos aumentan la posibilidad de ejercerla. Por otra parte, una contribución fija podría ser insoportable para quienes apenas satisfacen sus necesidades básicas. Basta imaginar que quienes tienen mayores ingresos, ejercitan sus libertades de manera más amplia, más se benefician de la cooperación social y más disfrutan de su poder económico. Asimismo, la igualdad estricta tampoco tomaría en cuenta las desigualdades en la capacidad de consumo o en el consumo efectivo. Si bien la premisa de la igualdad moral justifica un

${ }^{17}$ Cf. Dworkin (2000).

18 En coincidencia con Holmes y Sunstein (2011), para quienes las libertades dependen de una acción estatal que las proteja y regule. 
trato equitativo, no justifica una contribución exactamente igual. ${ }^{19}$

La concepción de la igual libertad de Ronald Dworkin merece una consideración aparte. Este autor interpreta la premisa de la igualdad moral de manera que exige tratar a las personas como igualmente importantes pero también igualmente responsables de sus proyectos de vida. Además niega la importancia prioritaria de los que están peor porque muchas veces ellos son responsables de encontrarse en esa situación y afirma que el principio de la diferencia "subvenciona las elecciones de los perezosos". Los tributos deberían imitar un sistema hipotético de seguros para compensar la mala suerte y lograr que cada persona pague el verdadero costo de oportunidad de los bienes que responsablemente ha decidido tener (Dworkin 1981, p. 294). Ahora bien, esta concepción de la igualdad y de la equidad tributaria no necesariamente ataca las enormes desigualdades de riquezas existentes. Solo serían gravadas progresivamente aquellas ganancias que no fuesen fruto de un ejercicio de responsabilidad de los individuos favorecidos. Dicho de otro modo, las ganancias que deben tributar progresivamente son las que provienen de la "buena suerte". En mi opinión, esta es una de las principales razones por las que la teoría de la igualdad de recursos dworkiniana no es satisfactoria desde un punto de vista igualitario. ${ }^{20}$

Según el principio de la diferencia, las ganancias de los ciudadanos mejor posicionados estarán justificadas si benefician a los peor posicionados. Uno podría suponer que el principio también debería aplicarse de manera inversa a las instituciones tributarias recaudatorias. Aquellos ciudadanos que obtienen mayores beneficios del ejercicio de sus libertades deberían contribuir progresivamente más para que se amplíe el disfrute y el consumo de bienes y servicios y consecuentemente mejore la calidad de vida de todos los ciudadanos. ${ }^{21}$ Pero la concepción rawlsiana de justicia propone un

${ }^{19}$ Las discusiones sobre la equidad y las diferencias relevantes para apartarse de la estricta igualdad parten del rechazo a un tributo de tasa plana; véase Murphy y Nagel (2004, pp. 13-14, 27).

${ }^{20}$ En otra parte analizo las implicancias tributarias de la igualdad de recursos y presento diferentes objeciones en su contra. Véase Fatauros (2014).

${ }^{21}$ De hecho esta interpretación maximalista es compatible con la primera formulación del principio de la igual libertad que exigía "el esquema más amplio de libertades". Sin embargo, este maximalismo sería una incorrecta aplicación de un criterio de prioridad dentro de un principio que persigue la igual libertad. En tanto todos los ciudadanos disfruten de igualdad estricta en el valor de libertades y oportunidades políticas, no se exige que el resto de las libertades sea asegurado en la misma extensión. Basta que exista una igualdad aproximada o que no exista una desigualdad sistemática y profunda. Igualmente, he analizado la aplicación de cargas más exigentes sobre los más capaces como una aplicación de las ideas del igualitarismo radical de John Roemer en Fatauros (2012). 
esquema diferente. En una "democracia de propietarios" las cargas tributarias deben ser proporcionales al nivel de consumo de cada ciudadano (aunque también pueden aplicarse proporcionalmente sobre los ingresos) y no deben tener como objetivo igualar el valor de las libertades que no son políticas. En contextos de igualdad aproximada, es equitativo que quienes consumen y gastan más deban contribuir proporcionalmente más.

En mi opinión, la proporcionalidad respeta la igualdad moral de las personas, el valor de la responsabilidad individual en el gasto y además no interfiere con las desigualdades en ingresos y riquezas que son justificadas por el principio de la diferencia. Primero, el consumo excesivo de bienes tiene el efecto de reducir las porciones distributivas de los demás. Cuando el consumo supera la porción equitativa de bienes, se produce una inequidad en la distribución y una disminución en las porciones distributivas de los demás. Segundo, es muy probable que quienes tienen un nivel de consumo muy elevado también tengan un nivel de ingresos muy elevado y, por lo tanto, los tributos aplicados sobre el consumo también tienen el efecto de aumentar proporcionalmente a medida que las personas ganan más dinero. De este modo, es razonable que los ciudadanos de una sociedad justa deban tributar de acuerdo a su nivel de consumo.

Debemos analizar la crítica de que los tributos al consumo son regresivos porque tienen un impacto mayor sobre el poder adquisitivo de los que menos tienen. Pero si las ganancias desiguales son el resultado de factores por los que los ciudadanos son responsables, este impacto no debería ser considerado inequitativo. Por un lado, si las ganancias están relacionadas con elecciones personales, el hecho de ganar menos es un hecho del que cada uno es responsable. Si esto es así, no queda claro por qué dos personas que consumen al mismo nivel en cantidad y calidad deberían pagar de acuerdo a lo que ganan y no a lo que consumen. Por otra parte, si están justificadas las desigualdades de ingresos económicos, esto es porque ellas son o el resultado de un ejercicio de responsabilidad, o de un mayor esfuerzo que el individuo realizó, o en todo caso porque estos ingresos compensan pérdidas que ha tenido una persona en el desarrollo de talentos que benefician a todos.

Afirmar que los ciudadanos deben contribuir impositivamente de acuerdo a sus consumos para restablecer la equidad exige una aclaración. El argumento presupone que los ciudadanos tienen la obligación de garantizar y mantener la equidad. Cuando alguna actividad invade las porciones distributivas de los demás, se excede la porción distributiva propia y se altera la equidad distributiva, generándose la obligación de restablecer la equidad. Si la actividad que altera la equidad es una 
actividad de consumo, entonces el restablecimiento de la equidad deberá estar vinculado a ese consumo. Es claro que no todo consumo invade las porciones distributivas ajenas, i.e. no necesariamente altera la equidad. Por lo tanto, el consumo no necesariamente genera una obligación de restablecer la equidad. ${ }^{22}$

La decisión de gravar los consumos se justifica sobre dos ideas normativas del liberalismo igualitario rawlsiano: la idea de ciudadano libre e igual y la idea de sociedad como empresa cooperativa. Los ciudadanos son normativamente concebidos como libres de planificar la satisfacción de sus preferencias (consumos) y como iguales a cualquier otra persona que goza un esquema de libertades y oportunidades semejante. La sociedad es normativamente concebida como una empresa cooperativa y productiva de bienes sociales y económicos para el beneficio recíproco. Tomadas en conjunción estas dos ideas exigen enfocarse sobre los tributos proporcionales al consumo.

El principio de igualdad equitativa de oportunidades ha sido interpretado por Samuel Freeman como un estándar que exige distribuir a los trabajadores la oportunidad de poseer propiedad privada sobre los medios de producción y de esta manera distribuir equitativamente el poder económico (Freeman 2006, pp. 107-108). Esta interpretación ha sido desafiada por Martin O`Neill, para quien el principio no exige una oportunidad de participar en la actividad productiva sino que tan solo regula la distribución de oportunidades de acceder a un puesto de trabajo y a una educación adecuada. Los argumentos ofrecidos por Freeman se ajustan mejor a la protección conjunta de las libertades y de las oportunidades sociales. La garantía del valor equitativo de las libertades políticas, que equivale a garantizar oportunidades equitativas (aproximadamente iguales) de participación política (es decir, ser escuchado y que la participación no dependa de las capacidades económicas de las personas) solo puede derivar de una aplicación conjunta de todos los principios de justicia distributiva. Dado que la participación política y el poder económico igual constituyen una parte importante de las bases del autorrespeto, su distribución necesariamente debe ser regulada por el primer principio de justicia.

Creo que estas consideraciones constituyen un argumento sólido en contra de los impuestos a las ganancias aplicados progresivamente y que tengan el fin de maximizar la posición de quienes reciben menos. Dentro de la concepción de la justicia como equidad los impuestos (progresivos) sobre las ganancias arbitrariamente obtenidas no tienen la

22 Agradezco la observación de un evaluador anónimo. 
función de incrementar la recaudación fiscal sino de disminuir dicha arbitrariedad moral. ${ }^{23}$ Además, suponiendo que la manera correcta fuese aplicar tributos sobre los ingresos, las personas beneficiadas por la aplicación del principio de la diferencia que ahora tienen mejores ingresos deberían pagar más tributos que cuando estaban peor. En síntesis, en una "democracia de propietarios", la recaudación fiscal es necesaria solo para garantizar condiciones vinculadas a dos parámetros absolutos: el costo de proveer los servicios públicos (cuyos costos no incrementan por el hecho de que aumenten los ingresos de los ciudadanos) y la satisfacción de necesidades básicas de su población (que debe superar un umbral para evitar la pobreza y satisfacer las necesidades básicas de los ciudadanos).

Asimismo, exigir más del que menos gana por los beneficios que recibe como condición para justificar las ganancias del que más gana, parece contraintuitivo. A la vez que se lo beneficia, porque de otro modo las desigualdades en ingresos serían moralmente injustificadas, se lo perjudica exigiéndole mayores contribuciones por un beneficio del que no es responsable. Los impuestos sobre las ganancias tendrían el doble efecto de mejorar la posición de los que están peor y a la vez empeorar esta misma posición.

Es por todo lo dicho que parece más razonable implementar un esquema de tributos proporcionales vinculados a los niveles desiguales de consumo individual. La proporcionalidad se aplicaría de manera uniforme sobre todos los ciudadanos. ${ }^{24}$ En la medida que dicho esquema sea neutral respecto de la libertad de ocupación y no afecte las decisiones relativas al trabajo, trata a todas las personas de manera igual.

El esquema rawlsiano de tributos ha sido objetado por Barbara Fried (1999) quien afirma que los ingresos de los ciudadanos no son tratados de manera uniforme ya que los tributos sobre el consumo no aplican la misma uniformidad que el principio de la diferencia (Fried 1999, p. 185). Fried acepta que los tributos proporcionales sobre el consumo tratan por igual a los ricos y a los pobres y lo único que juzga inaceptable es que precisamente sean los ingresos de quienes más ganan, los que deban beneficiar a quienes menos ganan. Mientras que los ciudadanos deben pagar gravámenes impositivos que se calculan (sobre los

${ }^{23}$ Cabe aclarar que para Rawls los impuestos sobre las ganancias sí pueden tener objetivos recaudatorios, siempre y cuando sean proporcionales y estén vinculados a alguno de los dos parámetros referidos. Agradezco a un evaluador anónimo traer a colación este punto.

${ }^{24}$ Incluso se afirma que el sistema tributario de una sociedad marcada por la injusticia debería tratar de modificar su estructura para aplicar un principio de progresividad en los tributos sobre el consumo. Véase McCaffery (1994, p. 296 y ss.). 
consumos pero también sobre los ingresos y por eso los que más ganan más pagan) tomando parámetros absolutos de riqueza, se realizan transferencias económicas para los que menos ganan tomando parámetros relativos de riqueza. Esto constituye, según Fried, una violación a la uniformidad en el trato. ${ }^{25}$

Si tomamos en consideración que todas las exigencias redistributivas rawlsianas están fundadas en consideraciones deontológicas, no hay nada extraño en sostener conjuntamente exigencias redistributivas fundadas en el principio de la diferencia y exigencias deontológicas fundadas en el trato igual. Sería inconsistente solo si pensamos que el principio de la diferencia tiene un fundamento consecuencialista maximizador. ${ }^{26}$ Pero incluso si existen ingresos desiguales, ellos pueden estar justificados para compensar sacrificios extras o costos de entrenamiento y no necesariamente deben satisfacer el principio de la diferencia.

Es necesario destacar algunas consideraciones relativas al funcionamiento general del esquema institucional tributario defendido por Rawls. Primero, los tributos proporcionales sobre el consumo solo pueden considerarse equitativos dentro de un marco institucional justo. $\mathrm{Su}$ aplicación supone que nadie tiene "necesidades básicas" insatisfechas y que todos los ciudadanos se encuentran en una posición política aproximadamente igual. Segundo, los mayores ingresos de los que más ganan están encadenados a las expectativas de los que menos ganan. Esto significa que el esquema satisface un ideal normativo de fraternidad social expresado en la idea de que nadie desea mayores ventajas a menos que esto también beneficie a los ciudadanos que están peor (Rawls 1971/1999, p. 90).

\section{Dos propuestas revisionistas sobre los tributos al consumo}

Ahora bien, ¿cuáles serían las exigencias tributarias concretas de la propuesta rawlsiana para sociedades cuyas instituciones se alejan del ideal de una "democracia de propietarios"? Dos recientes propuestas institucionales han sido elaboradas por Paula Casal y por Edward

25 Según Fried, la exigencia deontológica de uniformidad en el trato no se respeta adecuadamente. "En el contexto del esquema rawlsiano general, mi derecho a que mis ingresos no reciban un gravamen impositivo a una tasa marginal más alta que la que reciben los ingresos de mi vecino, representa una isla de derechos deontológicos empantanados en un mar de redistribución"(Fried 1999, p. 185).

${ }^{26}$ Lo he aclarado en Fatauros (2014). 
McCaffery. Casal (2012) examina el problema de la distribución global de recursos naturales y su vinculación con la contaminación. McCaffery (1994, 2006) defiende la sustitución de los tributos sobre las riquezas y sobre los ingresos por tributos sobre los consumos. A continuación se analizan ambas propuestas para evaluar si serían opciones atractivas para el liberalismo igualitario.

\section{IV.1. Argumento deontológico 1: equidad}

Casal defiende un principio de tributación progresiva sobre los consumos y argumenta que dichos tributos remedian las desigualdades económicas profundas y que no es cierto que coloquen mayor presión tributaria sobre quienes menos contaminan. Casal parte de caracterizar a los recursos naturales del siguiente modo: a) limitados, y competitivos, b) no producidos socialmente, c) esenciales para la vida humana, d) su explotación puede generar un daño irreparable, e) fácilmente redistribuibles por las instituciones, y f) susceptibles de ser usados por cualquier persona. Por ello, "los seres humanos tienen un derecho igual a una porción equitativa de recursos naturales" (geoísmo) y esos recursos deben ser distribuidos equitativamente. ${ }^{27}$

Alguien podría criticar esta teoría "geoísta" pensando en una distribución eficiente del derecho a consumir. Si alguien tiene mayor capacidad de reducir la contaminación y optimizar el consumo, ¿por qué no debería tener un derecho a una porción mayor de recursos? Desde una óptica que prioriza los beneficios para los que están peor, deberíamos aceptar que una explotación eficiente de los recursos naturales podría justificar una distribución desigual del derecho a consumir. Si lo que importa es el resultado del consumo y no el consumo en sí mismo, no deberíamos negar que esta justificación parece atractiva. Sin embargo, Casal niega que la eficiencia constituya un criterio relevante para distribuir recursos naturales, ya que esto privaría a los más ineficientes (en muchos casos los más pobres) de su legítimo derecho a una porción de recursos naturales.

27 Peter Vallentyne y Hillel Steiner mencionan que este principio ha sido sostenido por Hugo Grotius, Samuel Pufendorf, John Locke, William Ogilvie, Thomas Spence, Thomas Paine, Hippolyte de Colins, François Huet, Patrick E. Dove, Herbert Spencer, Henry George, Leon Walras y John S. Mill (citado por Casal 2011, p. 313, 2012, p. 3). Esto es independiente de si los demás bienes deben ser distribuidos equitativamente o no. 


\section{IV.2. Argumento deontológico 2: transparencia}

Otra estrategia argumentativa emprendida por Casal es apelar al principio de la responsabilidad individual. Según este principio, cada individuo debe asumir responsabilidad por las consecuencias de sus acciones y sus costos deben transparentarse pública e institucionalmente. El liberalismo igualitario tendría diferentes razones para favorecer un esquema así diseñado. Primero, los ciudadanos de una sociedad bien ordenada deberían tomar conciencia y asumir responsabilidad por las externalidades negativas que sus decisiones imponen sobre terceros (Casal 2012 , p. 4). No es justo que los costos generados por actividades lícitas sean soportados por la sociedad y no por quienes los producen. Segundo, los mecanismos que disminuyan las desigualdades inequitativas, no solo son permisibles sino que son requeridos. Los impuestos progresivos sobre el consumo medioambiental constituyen una herramienta adecuada para lograr promover la equidad y disminuir la injusticia. Sin embargo, es necesario mostrar en la práctica que dichos gravámenes no constituyen una injusticia agregada que repercutirá negativamente sobre la posición de quienes ganan menos. Ellos podrían tener opciones de consumo cada vez más caras.

El igualitarismo rawlsiano admite expresamente los tributos progresivos sobre los ingresos, pero su aplicación se restringe a las ganancias arbitrariamente obtenidas. En cambio desde una concepción como la de Dworkin, se podría argumentar de manera más directa que la exigencia de transparencia deriva de la exigencia de tratar a las personas como responsables. Sin embargo, no debemos menospreciar el valor de la reciprocidad implícito en la teoría de la justicia como equidad. La reciprocidad podría justificar la disuasión de los comportamientos predatorios que no solo invaden las porciones distributivas ajenas sino que también disminuyen el pozo social de recursos. Es por ello que una justificación que imponga los costos sociales y económicos a quienes de manera consciente se aprovechan de los recursos para obtener una ventaja inequitativa parece más razonable.

Debemos reconocer que gravar progresivamente los consumos perniciosos debería justificarse de otro modo ya que estos tributos no comparten la justificación de los tributos sobre las ganancias equitativamente obtenidas, ni de los tributos sobre las ganancias arbitrariamente obtenidas. Este tipo de medidas pretende cambiar la estructura motivacional de los ciudadanos. Estos son los impuestos que mejor ejemplifican la propuesta de Casal y no creo que sean incompatibles con el sistema tributario promovido por la teoría rawlsiana de la justicia. Puede que sea realmente difícil calcular los costos futuros y eventuales 
de algunas actividades como el consumo de $\mathrm{CO}_{2}$ y no obstante, para fortalecer el efecto disuasivo, los impuestos tengan una alícuota que supere ampliamente los costos de las externalidades negativas. Este tipo de tributos podría utilizarse para desalentar un rango enorme de actividades cuya peligrosidad dependerá del desarrollo y los recursos disponibles de cada sociedad.

\section{IV.3. Argumento teleológico: efectos del consumo}

Según otra postura, defendida por el tributarista Edward McCaffery, gravar los ingresos no es una solución adecuada para confrontar la acumulación desmesurada de riquezas y la consecuente desigualdad de oportunidades y de poder que se genera. En contradicción con la mayoría de los igualitarios, este autor sostiene que debe promoverse la generación y acumulación de riquezas y que las desigualdades en el consumo de recursos solo son inequitativas si producen resultados injustos (McCaffery 1994). Para este autor el modo en que se utiliza la riqueza es más preocupante que la institución de la herencia y la generación de ganancias desiguales porque los efectos de utilizar o consumir la riqueza puede amenazar la equidad del sistema. En este sentido, la posesión de riquezas es moralmente problemática solo cuando se generan beneficios $\mathrm{y}$ ventajas inequitativas.

El argumento apela a las consecuencias negativas que podrían provocar los tributos sobre la mera posesión o transmisión de la riqueza (McCaffery 1994, pp. 286-289). Primero, gravar las transmisiones mortis causae podría incentivar las transferencias intervivos o la constitución de fideicomisos. Esto podría ser hecho con la finalidad de evitar los impuestos a las herencias. Segundo, las transferencias gratuitas intervivos podrían generar profundas desigualdades en el esquema de oportunidades sociales. La riqueza heredada tiene mayor impacto sobre las oportunidades sociales a medida que los beneficiarios son más jóvenes. Por el contrario, a medida que su edad aumenta, sus decisiones pasadas son más importantes para determinar su futuro y sus oportunidades. Tercero, asumiendo que no existen tributos sobre el consumo, gravar la transmisión hereditaria de bienes incrementa los incentivos para que las personas consuman sus bienes por completo e intenten evitar pagar impuestos a la herencia. McCaffery concluye que los tributos sobre las herencias deberían ser sustituidos. ${ }^{28}$ Además, el incremento del consumo exigiría instaurar

${ }^{28}$ McCaffery cita a Joseph Stiglitz y Amartya Sen como economistas que destacan las consecuencias negativas que podría tener el consumo realizado por los más ricos. 
instituciones que promuevan la acumulación de capital y las inversiones financieras, por ejemplo, ofreciendo intereses más altos. Si el Estado dirigiese sus esfuerzos a promover el ahorro esto podría reducir los recursos sociales destinados a la producción o al incentivo de otras actividades socialmente valiosas (McCaffery 1994, p. 293).

Igualmente si nos tomamos en serio la metáfora de los bienes sociales como "bienes que forman parte de un pozo común" deberíamos incrementar el control sobre el uso de los bienes y no sobre la mera posesión, vigilando especialmente aquellas actividades relacionadas con el agotamiento del bien y su exclusión del pozo social común. Según McCaffery deberíamos distinguir entre posesión y uso de los bienes (McCaffery 1994, pp. 297-302). ${ }^{29}$ Mientras que los impuestos que gravan la riqueza (ganancias, capital y transferencias mortis causae) se concentran en el aspecto estático, los impuestos sobre los consumos (al valor agregado, a las transferencias financieras) se concentran en el aspecto dinámico. Los tributos sobre las ganancias gravan la riqueza disponible para el consumo. Para evitar gravar la riqueza que no está disponible para el consumo y que se destina, por ejemplo, a gastos de mantenimiento, los impuestos sobre las ganancias suelen incorporar deducciones y excepciones personales. ${ }^{30}$ En favor de los tributos sobre el consumo, McCaffery señala que ellos únicamente gravan la porción de riquezas que de hecho es consumida. ${ }^{31}$

Entre ellos enumeran: el aumento de precios de bienes básicos para la supervivencia, el aumento del precio del acceso a bienes públicos, de tal modo que "la aparición y la participación pública" se convierte en "vergonzosa" para quienes no tienen dinero. Véase McCaffery (1994, pp. 290-291), de hecho esta ha sido también una objeción en contra del ideal de la igualdad democrática que defiende Elizabeth Anderson (Anderson 1999), cf. Knight (2010).

${ }^{29}$ McCaffery piensa que la razón por la que se gravan las herencias es la desigual posesión de riquezas entre los ciudadanos. Sin embargo, las herencias podrían gravarse por otras razones. De hecho, el argumento rawlsiano para gravar las herencias no hace hincapié en la posesión sino en el hecho de que la obtención de estos ingresos es un hecho moralmente arbitrario.

${ }^{30}$ Este es el caso del sistema argentino en donde se incorporan rubros que pueden ser deducidos de los impuestos a las ganancias. En un trabajo posterior, McCaffery distingue tres tipos de tributos: sobre los ingresos, sobre los consumos pero que se pagan ex ante, y sobre los consumos que se pagan ex post. Los tributos sobre los ingresos incorrectamente gravan doblemente a las personas que ahorran, y por eso corresponde incorporar deducciones y excepciones personales ya que no todo el dinero que ingresa en el patrimonio de una persona es dinero que está disponible para el consumo. Así se grava solo la parte de los ingresos que luego serán consumidos, pero de una manera previa al momento del consumo. Véase McCaffery (2006, pp. 169-173).

31 El autor toma la definición Haig-Simons de ingresos (o renta) según la cual las ganancias de una persona (I) equivalen a la suma de sus ahorros (A) y sus consumos 
Según este autor, al aumentar los consumos y disminuir el ahorro se perjudica a los ciudadanos menos aventajados. Por un lado, los ciudadanos más ricos tienen mayores incentivos para utilizar su riqueza en beneficio propio y no para contribuir a la cooperación social. Por otro lado, si los ciudadanos más ricos actúan motivados para evitar pagar más, la recaudación de los tributos sobre la riqueza y las herencias disminuye y se reduce la recaudación fiscal. Esto puede provocar un desmejoramiento en la provisión de servicios sociales que son mayormente utilizados por los ciudadanos más pobres.

Esta postura liberal no comparte la idea de que las ganancias arbitrariamente obtenidas puedan amenazar la igualdad equitativa de oportunidades (McCaffery 1994, pp. 291-293). Su escepticismo se basa en un argumento pragmático: tal como están organizadas las instituciones no existen oportunidades equitativas y por lo tanto no existen ganancias equitativas. Este argumento parece rechazar la distinción entre desigualdades económicas arbitrarias y no arbitrarias. No obstante, McCaffery parece soslayar que la idea de ganancias equitativas, en una sociedad justa, simplemente refiere a las expectativas (institucionalmente generadas) de recibir una recompensa por un trabajo determinado. Dichas expectativas son legítimas si el sistema funciona como un mecanismo de justicia procesal pura.

De cualquier modo, tanto las ganancias equitativas como las ganancias inequitativas podrían poner en peligro la equidad de las libertades políticas y las oportunidades sociales. Esta amenaza podría ser causada por el financiamiento ilegítimo de campañas políticas, la amplificación de una opinión política en desmedro de otras, por consumos rápidos y a gran escala que pueden desequilibrar el sistema económico de mercado, como así también el consumo de objetos contaminantes, o las inversiones irracionales que empeñan el bienestar económico de las generaciones futuras (McCaffery 1994, pp. 291-292, 301).

El argumento adquiere mayor solidez si consideramos que pueden existir buenas razones para desear la acumulación de riquezas, como por ejemplo, la promoción de emprendimientos empresariales o la generación de empleo en un sector industrial determinado.

(C). Las ganancias, o bien se consumen, o bien no se consumen; por lo tanto, o bien se consumen, o bien se ahorran. El axioma ( $\mathrm{I}=\mathrm{A}+\mathrm{C})$ implica $(\mathrm{C}=\mathrm{I}-\mathrm{A})$. Los consumos de una persona son equivalentes a la porción de ingresos que ha sido dispuesta para gastar una vez que han sido deducidos los ahorros. Henry C. Simons, Personal Income Taxation, Chicago, Chicago University Press, p. 58, citado por McCaffery (1994). 


\section{IV.4. Autorrespeto y reciprocidad cívica}

Ahora bien, para rebatir estos últimos argumentos es necesario distinguir aquellos efectos que se producen en una "democracia de propietarios" y en una sociedad injusta, respectivamente. Así se podrá identificar mejor la función de la institución que se pretende criticar y reformar. En ambos casos la propuesta de McCaffery es un esquema de tributación progresiva sobre el consumo.

En el caso de las sociedades justas, McCaffery critica el sistema de tributos progresivos sobre las herencias. Es legítimo preguntarse por qué se justifica que una persona pueda heredar una cantidad exorbitante de dinero. De acuerdo con la interpretación defendida a lo largo de este trabajo, la respuesta surge de la aplicación del principio de la diferencia. $\mathrm{O}$ bien la desigualdad económica resultante beneficia económicamente a los que están peor o bien no lo hace. En el primer caso está justificada, en el segundo, no. Pero ninguna herencia está moralmente justificada en tanto represente una desigual oportunidad de ejercer libertades políticas $\mathrm{u}$ oportunidades sociales.

Alguien podría admitir el argumento de la equidad pero negar que la equidad tributaria se vincule con las bases del autorrespeto. Quien plantea este argumento supone que existe una independencia entre las condiciones morales que el esquema institucional tributario y el resto de las instituciones sociales deben satisfacer. Este problema ha sido identificado como "miopía moral" y ha sido discutido extensamente por Murphy y Nagel (2004). Por mi parte, no creo que alguien que defiende la igualdad moral de las personas pueda aceptar esta premisa. El valor más importante detrás del principio de equidad tributaria es la igualdad de los contribuyentes, que incluso en su interpretación más formalista, exige tratar a los situados en circunstancias semejantes de manera semejante. Si a dos contribuyentes en circunstancias semejantes se les exigiesen montos diferentes, quien recibe la mayor carga tendría una queja razonable y legítima vinculada a la igualdad de trato. Dadas estas consideraciones, la conexión entre la igualdad de trato, la equidad tributaria y el autorrespeto es suficientemente explícita. ${ }^{32}$

En el caso de las sociedades injustas, lo que se critica es el sistema de tributos progresivos sobre las ganancias y el capital o, de modo más genérico, el sistema de tributos sobre la riqueza. El problema de un esquema de tributos progresivos sobre el consumo es que estos no remedian la inequidad que se produce cuando los ciudadanos más ricos obtienen sus

32 Esta es una respuesta a la objeción planteada por un evaluador anónimo. 
ingresos en circunstancias de inequidad política y social. Esta inequidad constituye un problema fundamentalmente político ya que la desigualdad económica deriva de una previa desigualdad política y social. Es más, la desigualdad política y social se ve reforzada por la desigualdad económica resultante. Quien obtiene mejores ingresos porque tiene mejores oportunidades de hacer escuchar su opinión traduce estas oportunidades en mayores ventajas económicas y cristaliza su posición privilegiada.

Peor aún, la desigualdad económica inequitativa vulnera el ideal de fraternidad y amistad cívica ínsita en una "democracia de propietarios". Paradigmáticamente, el modo de obtener ventajas inequitativas consiste en el disfrute de oportunidades desiguales a sabiendas de que es injusto aprovechar estas oportunidades para disminuir la posición de los más desaventajados. Cuando en una sociedad es de conocimiento público que solo algunos ciudadanos tienen la posibilidad de realizar consumos ilegítimos, extravagantes, imprudentes o decadentes existe una injusticia pública. En primer lugar, el mero hecho de la desigualdad en el consumo indica una diferencia injustificada en el ejercicio del poder económico. En segundo lugar, el hecho de que esta diferencia injustificada sea pública y notoria señala la existencia de una categoría de ciudadanos que no tiene la capacidad económica para alterar la vida de los demás o para consumir su riqueza del modo que ellos deseen.

La equidad es un valor que no solo debe verse realizado sino que debe verse públicamente realizado para que todos conozcan que las instituciones tratan a todos con igualdad (Christiano 2008). Por ejemplo: Álvarez gana muchísimo dinero lícitamente, mientras que Borges gana lo suficiente para cubrir sus necesidades básicas y para ahorrar un poco. Álvarez tiene tanto dinero que podría adquirir la compañía en la que trabaja Borges, despedirlo por razones arbitrarias e indemnizarlo. Borges no tiene ninguna chance similar de controlar la vida de Álvarez de este modo, y frente a este hecho, es comprensible y razonable que Borges sienta que las instituciones no lo tratan como un ciudadano igual a los demás.

Alguien podría replicar que las bases del autorrespeto no se lesionan por la mera desigualdad económica. En este punto es necesario destacar que no es posible garantizar las bases del autorrespeto con una distribución más o menos equitativa de bienes económicos. Por el contrario, lo que se necesita es garantizar institucionalmente y de modo público el valor de la igualdad (Christiano 2008, p. 46 y ss.).

No afirmo que las bases del autorrespeto se vulneren solo cuando existe una relación de dominación. La dominación política es solo una de las formas en que se puede vulnerar dicho valor. Otra manera de vulnerarlo se configura por el trato institucional que reciben los 
ciudadanos. Las instituciones deben apuntar a que las personas se vean como ciudadanos iguales y que esta autopercepción sea pública. Porque, si solo algunos ganan lo suficiente como para que sus vidas sean significativamente mejores y solo ellos tienen la oportunidad de realizar actividades que tengan un impacto enorme sobre los demás ciudadanos, entonces la igualdad es sospechosa. Incluso aunque no aprovechen sus ventajas inequitativas, la mera posibilidad de afectar la vida de otras personas sin que ellas puedan neutralizar o responder a esta amenaza, socava las bases del autorrespeto, de la igualdad y de la fraternidad que debe ser parte de las relaciones entre ciudadanos libres e iguales. ${ }^{33}$

McCaffery podría replicar este argumento haciendo hincapié en la idea de "pozo común de recursos sociales". Así, podría defender los tributos sobre el consumo afirmando que ellos permiten concentrarse solo en el modo en que se utilizan los bienes. Este tributo redefine la idea de bienes públicos poseídos privadamente, los que jamás dejarán de ser gravados. Es decir, el consumo se produce (y se grava) cuando se retiran recursos del "pozo común". Sin embargo, la equidad en el valor de las libertades políticas y la igualdad equitativa de oportunidades sociales no puede lograrse mediante la aplicación de gravámenes sobre el consumo porque, pese a su progresividad, ellos impactan sobre el patrimonio de las personas cuando las desigualdades ya han sido producidas y las ventajas inequitativas ya han sido aprovechadas. Por ello, no importa cuánto pueda recaudar el gobierno, aplicando un tributo progresivo sobre el consumo, importa cómo la desigualdad económica afecta la igualdad política y social. Finalmente, la igualdad no peligra solamente cuando las personas hacen un uso moralmente reprochable, es decir, cuando consumen de manera inequitativa. Esta igualdad se lesiona cuando se obtienen estos recursos haciendo público lo que constituye un aprovechamiento de oportunidades desiguales y un ejercicio de un desigual poder político permitido por las instituciones jurídicas y sociales.

\section{Conclusiones}

Los tributos progresivos sobre el consumo de recursos naturales no pueden reemplazar a los tributos sobre las ganancias. A lo sumo enfrentan el hecho de que algunas actividades lícitas provocan externalidades negativas sobre terceros. Obviamente, cuando los que sufren las externalidades son los más pobres, transparentar los costos ocultos, disminuir las actividades perniciosas y distribuir correctamente las

${ }^{33}$ Este punto responde a la objeción de un evaluador anónimo. 
responsabilidades es lo correcto. ${ }^{34} \mathrm{Si}$ el gobierno pretende llevar adelante estos objetivos y adicionalmente recaudar más para mejorar la situación de los que peor están, los tributos progresivos sobre el consumo de recursos naturales parecen una herramienta institucional adecuada. Pero esto no evita las acumulaciones hereditarias de capital ni garantiza oportunidades sociales equitativas para todos.

Cuando el consumo genera consecuencias decadentes, es imprudente o está justificado en gustos extravagantes, sería moralmente aceptable aplicar tributos progresivos para transparentar los costos ocultos que provocan dichas actividades y también disuadirlas. El que algunas actividades sean más costosas que otras no es per se una violación a la neutralidad liberal. En primer lugar, imponer tributos para distribuir los costos ocultos es una exigencia de una "democracia de propietarios" que aspira a desarrollar ciudadanos autónomos y responsables. De no hacerlo, la propiedad de algunos ciudadanos se vería perjudicada injustamente. En segundo lugar, la disuasión de conductas está moralmente justificada porque dicha medida se vincula con un objetivo y un interés público: disminuir los gastos en salud, promover la higiene pública, aumentar la seguridad pública o proteger los recursos naturales. En estos casos, la justificación de las cargas extras de una cierta actividad estaría justificada para cualquier ciudadano que pueda comprender el tipo de objetivos por las que se intenta disuadir. ${ }^{35}$ Alguien podría contraargumentar que esto viola la neutralidad de un Estado liberal. Sin embargo, si la aplicación de dichos tributos se basa en razones públicas aceptables desde el punto de vista del ciudadano libre e igual entonces no hay lugar para la objeción de parcialidad. ${ }^{36}$

En situaciones de injusticia contextual que se alejan del ideal de una "democracia de propietarios" los ciudadanos más ricos gozan de ventajas inconmensurables. Ellos podrían utilizar sus bienes para generar utilidades y a la vez eludir los tributos sobre las ganancias. Por ejemplo, los tributos sobre las ganancias provenientes del trabajo dejan a salvo las provenientes de ahorros o inversiones financieras; pueden recurrir a préstamos que son cancelados cuando se liquida el patrimonio de la sucesión. En vista de estos problemas, parece razonable

${ }^{34} \mathrm{El}$ incremento de tributos sobre el consumo puede ser una solución para los problemas de coordinación relativos al consumo de bienes que representan ventajas posicionales (Halliday 2013, pp. 1112-1114).

35 Agradezco las observaciones de un evaluador anónimo en este punto.

36 Dado que el consumo ambiental provoca externalidades negativas obvias, la justificación de los tributos progresivos sobre el consumo ambiental parece fácilmente justificable y políticamente atractiva (Casal 2012, pp. 5-6). 
complementar el sistema de principios tributarios de una sociedad injusta. Pese a sus buenas intenciones, la propuesta de McCaffery -completa sustitución de los impuestos sobre los ingresos, las riquezas y las herencias- no da cuenta de las inequidades en la obtención de ganancias y en el aprovechamiento de ventajas desiguales. Por eso debemos rechazarla. El esquema tributario sobre los ingresos y la riqueza no tiene como único objetivo la recaudación fiscal. Además, el uso que las personas le den a sus ganancias injustamente obtenidas es moralmente relevante precisamente porque son injustamente obtenidas. Un gobierno justo debería eliminarlas (gravándolas o impidiéndolas) porque los ciudadanos las obtienen a partir de explotar fallas en la configuración de las principales instituciones sociales.

El liberalismo igualitario no debería soslayar los impuestos sobre el consumo y, de hecho, Rawls piensa que "serían parte del mejor esquema de tributos"(Rawls 1971/1999, p. 246). Pero este interés presupone que las instituciones llevan adelante una distribución equitativa de libertades y oportunidades sociales, riquezas e ingresos. Cuando no se satisface este ideal, las ganancias injustamente obtenidas son injustas, aun cuando la aplicación de gravámenes progresivos sobre los ingresos desincentiven a las personas más talentosas y los menos aventajados estén peor.

El análisis realizado permite comprender mejor por qué no están justificadas las desigualdades económicas cuando peligran las libertades básicas, las libertades políticas o las oportunidades sociales. El tipo de mecanismos adecuados para realizar las condiciones sociales que permitan satisfacer los principios de justicia gravan ciertos tipos de ganancias, las arbitrariamente obtenidas (herencias y donaciones). Cuando las instituciones no son justas se requieren soluciones institucionales que en otros casos serían vistas como moralmente inaceptables. Por ejemplo, cuando las personas se aprovechan de injusticias institucionales es moralmente permisible imponer tributos progresivos sobre sus ganancias inequitativamente obtenidas.

La "democracia de propietarios" exige implementar tributos progresivos sobre el consumo de recursos naturales, siempre y cuando fuese posible demostrar su efectividad como mecanismo para disuadir este consumo. Asimismo, si lo que se pretende es transparentar el costo individual que debería incorporarse en la producción de externalidades negativas, entonces es moralmente correcto el gravamen. Esto forma parte de la equidad tributaria. Sin embargo, la propuesta de basar el esquema institucional tributario exclusivamente en tributos sobre el consumo no es plausible por las razones expresadas. Sobre la propuesta de McCaffery es necesario concluir que no es posible erradicar los peligros 
que supone la acumulación de riquezas, ni siquiera implementando tributos progresivos sobre los consumos. Otros mecanismos impositivos son indispensables.

\section{Bibliografía}

Alstott, A. L. (2007), "Equal Opportunity and Inheritance Taxation", Harvard Law Review, 121 (2), pp. 469-542.

Anderson, E. S. (1999), “What Is the Point of Equality?”, Ethics, 109 (2), pp. 287-337.

Barry, B. M. (1989), Theories of Justice, Berkeley, University of California Press.

Casal, P. (2011), "Global Taxes on Natural Resources", Journal of Moral Philosophy, 8 (3), pp. 307-327.

Casal, P. (2012), "Progressive Environmental Taxation: A Defence", Political Studies, 60 (2), pp. 419-433.

Christiano, T. (2008), The Constitution of Equality: Democratic Authority and Its Limits, Oxford, Oxford University Press.

Cohen, G. A. (2009), Why Not Socialism?, Princeton, Princeton University Press.

Dworkin, R. (1981), "What is Equality? Part 2: Equality of Resources", Philosophy and Public Affairs, 10 (4), pp. 283-345.

Dworkin, R. (2000), Sovereign Virtue: The Theory and Practice of Equality, Cambridge, Harvard University Press.

Elkins, D. (2006), "Horizontal Equity as a Principle of Tax Theory", Yale Law \& Policy Review, 24 (1), pp. 43-90.

Fatauros, C. (2012), "Igualdad de oportunidades y tributo sobre los talentos: un enfoque sobre las capacidades productivas desde la óptica de la responsabilidad", Anuario XIII del Centro de Investigaciones Jurídicas y Sociales, Buenos Aires, La Ley.

Fatauros, C. (2014), "La justicia distributiva y la relevancia moral de la suerte", (tesis doctoral entregada para su evaluación), Facultad de Derecho y Ciencias Sociales, Universidad Nacional de Córdoba.

Freeman, S. (2006), Justice and the Social Contract: Essays on Rawlsian Political Philosophy, Oxford, Oxford University Press.

Freeman, S. (2007), Rawls, Londres-Nueva York, Routledge.

Fried, B. H. (1999), "The Puzzling Case for Proportionate Taxation", Chapman Law Review, 2 (1), pp. 157-261.

Halliday, D. (2013), "Justice and Taxation", Philosophy Compass, 8 (12), pp. 1111-1122.

Hart, H. L. A. (1961), The Concept of Law, Oxford, Clarendon, $2^{\mathrm{a}} \mathrm{ed}$. 
Holmes, S. y Sunstein, C. R. (1999), The Cost of Rights: Why Liberty Depends on Taxes, Nueva York, W.W. Norton. [Trad. Holmes, S. y Sunstein, C. R., El costo de los derechos: Por qué la libertad depende de los impuestos, Buenos Aires, Siglo Veintiuno, 2011.]

Jackson, B. (2012), "Property-Owning Democracy: a Short History", en O'Neill, M., y Williamson, T. (2012).

Knight, C. (2010), Luck Egalitarianism: Equality, Responsibility, and Justice, Edimburgo, Edinburgh University Press.

McCaffery, E. J. (1994), "The Political Liberal Case Against the Estate Tax", Philosophy \& Public Affairs, 23 (4), pp. 281-312.

McCaffery, E. J. (2006), “The Uneasy Case for Capital Taxation”, en Paul, E. F., Miller, F. D. y Paul, J., Taxation, Economic Prosperity, and Distributive Justice, Cambridge, Cambridge University Press.

Meade, J. E. (2013), Efficiency, Equality and the Ownership of Property, Routledge.

Mill, J. S. (2001), Utilitarianism, Indianápolis-Cambridge, Hackett.

Moreso, J. J. y Vilajosana Rubio, J. M. (2004), Introducción a la teoría del derecho, Madrid, Marcial Pons.

Murphy, L. y Nagel, T. (2004), The Myth of Ownership: Taxes and Justice, Oxford, Oxford University Press.

Nozick, R. (1974), Anarchy, State, and Utopia, Nueva York, Basic Books.

Olson, K. A. (2010), "The Endowment Tax Puzzle", Philosophy \& Public Affairs, 38 (3), pp. 240-271.

O'Neill, M. (2009), "Liberty, Equality and Property-Owning Democracy", Journal of Social Philosophy, 40 (3), pp. 379-396.

O'Neill, M. y Williamson, T. (eds.) (2012), Property-owning democracy: Rawls and beyond, Maiden,Wiley-Blackwell.

Rawls, J. (1971/1999), A Theory of Justice: Revised Edition, Cambridge, Belknap Press of Harvard University Press.

Rawls, J. (1999), "Unidad social y bienes primarios", en Justicia como equidad: Materiales para una teoría de la justicia, Madrid, Tecnos.

Rawls, J. (2001), Justice as Fairness: a Restatement, Kelly, E. (ed.), Vol. 1, Cambridge, Harvard University Press.

Rivera López, E. (1996), “Es el trilema de Fishkin un verdadero trilema?”, Análisis Filosófico, 16 (1), pp. 27-41.

Rivera López, E. (2007), "Igualdad, libertad y mérito: ¿valores en conflicto?", en Alegre, M. y Gargarella, R. (eds.) (2007), El derecho a la igualdad: Aportes para un constitucionalismo igualitario, Buenos Aires, Lexis Nexis.

Roemer, J. E. (1996), Theories of Distributive Justice, Cambridge-Londres, Harvard University Press. 
Roemer, J. E. (1998), Equality of Opportunity, Londres, Harvard University Press.

Seleme, H. (2005), "El valor de la igualdad: Explorando el argumento de Farrel", Estudios Públicos, 98, pp. 143-170.

Shaviro, D. (2002), "Endowment and Inequality", en Thorndike, J. J. y Ventry, D. J., Tax Justice: The Ongoing Debate, Washington, Urban Institute Press.

Slemrod, J. y Bakija, J. M. (2008), Taxing Ourselves: a Citizen's Guide to the Debate over Taxes, Cambridge, The MIT Press.

Stark, K. (2005), "Enslaving the Beachcomber: Some Thoughts on the Liberty Objections to Endowment Taxation", Canadian Journal of Law \& Jurisprudence, 18 (1), pp. 47-68.

Steiner, H. (2011), "The Global Fund: A Reply to Casal”, Journal of Moral Philosophy, 8 (3), pp. 328-334.

Sugin, L. (2010), "A Philosophical Objection to the Optimal Tax Model", Tax Law Review, 64, pp. 229-551.

Vallentyne, P. (2007), "Libertarianism and the State", Social Philosophy and Policy, 24 (1), pp. 187-205.

Vallentyne, P. (2012), "Taxation, Redistribution and Property Rights", en Marmor, A. (ed.), Routledge Companion to Philosophy of Law, Routledge.

Van Parijs, P. (1992), ¿Qué es una sociedad justa?: Introducción a la práctica de la filosofía política, Buenos Aires, Nueva Visión.

White, S. (2003), The Civic Minimum: On the Rights and Obligations of Economic Citizenship, Nueva York, Oxford University Press.

Williamson, T. y O'Neill, M. (2009), "Property-Owning Democracy and the Demands of Justice", Living Reviews on Democracy, 1, pp. 1-10. Recuperado de http://democracy.livingreviews.org/index.php/ lrd/article/view/lrd-2009-5/16 (23/02/16).

Recibido el 15 de septiembre de 2014; aceptado el 27 de marzo de 2015 